\title{
The Role of Social Media in the Intercultural Adaptation of Pekanbaru Immigrants
}

\author{
Tessa Shasrini \\ tessashasrini@comm.uir.ac.id \\ Faculty of Communication, Universitas Islam Riau, Indonesia \\ Yudi Daherman \\ yudidaherman@comm.uir.ac.id \\ Faculty of Communication, Universitas Islam Riau, Indonesia
}

\begin{abstract}
The part of Social Media within the handle of cultural adjustment plays an awfully critical role. Immigrants to remote societies have connected different advances to help them in social adjustment and accularation forms. In later a long time, the foremost common procedure and valuable that newcomers utilize is social media, which plays a part vital in interfacing individuals around the world together to share and trade information and social conventions. This inquire about points to discover out the part of Social Media on the intercultural adjustment of Pekanbaru migrants. By utilizing the method qualitative clear through interviews with workers at the Pekanbaru Rudenim. Comes about from this ponder is that within the adjustment handle carried out by immigrants going through a few phaes, vacation stages, culture stun, determination and integration. Social media It has been utilized among vagrants to preserve contact with family individuals and companions in their domestic nation.
\end{abstract}

Keywords: Social Media; Intercultural Communication; Cultural Adaptation; Immigrant

\section{INTRODUCTION}

The impact of social media is getting to be an progressively well-known component of our lives standard of living in today's worldwide society. Social media is an vital portion of life since it advances interconnecting between people, and is mutuly reliance of our socially diverse world. In today's society, there are increment within the number of Iemet clients so that modern social media are becoming more well known in every day designs and schedules. Intercultural adjustment includes the method of advancing understanding through interaction so that the requests of the modern social environment can be met. A few thinks about appear that individuals tend to utilize social media to gotten to be more coordinates into have culture amid their adjustment and to preserve associations to the domestic nation they. On the issue of intercultural adjustment. Intercultural studies focus on the interactions between people from different cultures different cultural backgrounds, and according to Gudykunst (2003), adaptation is a "process dynamic in which the individual, after moving to an unfamiliar cultural environment, build (or rebuild) and maintain relatively stable. reciprocal relationships turning, and functional with the environment".

The displaced person sis has driven the fast advancement of inventive advances and applications of media. Whereas societies around the world esteem conventions, convictions 
and standards their independence that produces them interesting, social media interfaces individuals all through the world notwithstanding of geological contrasts and boundaries. Concurring to Chen and Zhang (2010). The compression of time and space, due to the meeting of unused media and globalization, has shrivels the world into a much littler intelligently field". Individuals all over universes can connected with each other inside seconds of sending and accepting message. Social media has brought individuals from distinctive societies together in a "worldwide village".

During intercultural adjustment to the have country's environment, people utilize social media to memorize around their have nation, construct and keep up compatibility, and remain educated with occasions in their domestic nation. With Hence, it is vital to look at the potential affect of social media on adjustment between culture to superior get it the part of unused innovations within the handle of intercultural communication in this worldwide society. Within the concept of migration, it is clarified that the development of individuals from one nation to another is other countries, with yearnings of needing to live forever, are alluded to as foreigners (KBBI, 2002). These remote workers tend to move from one nation to another in groups, both little and huge scale with the most objective of needing to settle in a recently recognized nation that's known to be more conducive and promising in terms of different things.

The Immigration Detention Center (Rudenim) is a shelter where the quarantine for immigrants who enter Indonesian territory illegally do not have official documents such as passports and visas. Illegal immigrants or foreigners who violating the law will stay temporarily in the Rudenim and they are called detainees. This Rudenim is beneath the support of the Diretorate Common of Migration. Rudenim in Indonesia are spread in different cities, counting Jakarta, Medan, Pekanbaru, Batam, Semarang, Surabaya, Pontianak, Balikpapan. Manado, Denpasar, Kupang, Makassar, and Jayapura. Unlawful Migrants who are within the Migration Detainment Center (Rudenim) Pekanbaru city based on the information gotten comprised of citizens of Afghanistan, Pakistan, Iran, Iraq, Palestine, Bangladesh, Sudan, and Nepal. Unlawful Foreigners citizens of Afghanistan beginning are most of them possessed the movement detainment house. The presence of immigrants in Pekanbaru trigger the emergence of intercultural communication in Pekanbaru, especially in Rudemin and surroundings. Illegal Immigrant Life in Pekanbaru City when facing the environment new social culture they are aware of what to do in adjustment. That matter can be known through the knowledge gained. but each individual has character and the way each of them solves certain problems they face in particular in adjustment..

\section{LITERATUR REVIEW}

\section{Intercultural Adaptation}

Adjustment to a modern culture may be a energetic prepare by which an person, after moving into an new social environment, construct (or revamp) and maintain moderately steady, corresponding connections complementary, and utilitarian with the environment" (Gudykunst, 2003, p.244). Adjustment to a new culture includes encountering numerous components within the handle of adjustment, such as behavioral and mental changes due to individuals from differing societies connected with each other in different conduct (Kim, 2005). According to Lee, Kim, Lee, and Kim (2012), people have to be apply versatile aptitudes and investigate information around modern culture when locks in within the focused on culture. This prepare incorporates having mindfulness a clear understanding of one's culture and the modern culture in terms of contrasts and likenesses. For illustration, being inquisitive and being open to social 
contrasts makes a difference improvement of intercultural competence. In expansion, communication is exceptionally imperative within the prepare between these societies, where communicating with individuals in a unused culture is exceptionally valuable for breaking down barriersrst, and after that altering slowly to a unused culture.

The stages of intercultural adjustment are critical to consider when drawing associations to social media utilize. The four stages are special night, emergency, alteration, and biculturalism (Lysgaard, 1955). Amid the special first night organize individuals involvement starting happiness by being overseas in a distinctive nation. The emergency organize comprises of threatening vibe and dissatisfaction with living in an new culture. At that point there are alterations and slow recuperation, and biculturalism is full alteration and adjustment. Such that As Kohls (2001) focuses out, culture stun is "the mental confusion experienced by a few incredible individuals when they move for a long time into very different cultures of their culture" (p. 91). Culture shock is an obstacle that is felt by everyone during intercultural adaptation that can affect their communication and behavior. Moreover, communication is an important characteristic of this intercultural process. Because many people migrate to study, work and live, talk to others before and after being in a new environment. Learn as much as you can about other cultures and the processes between significant cultural traits that influence adjustment and emotion. In addition, having emotional control to suggest skills for participation in learning and understanding as well as being more open and flexible in getting used to adapting to other cultures (Matsumoto, Hirayama \& LeRoux, 2006).

To be successful in communicating with people from different cultures, one must be able to develop communition competence skills (Chen and Starosta. 1996, 2005). Global communication competence is an important skill that must be developed to be able to help us understand other cultures and communicate successfully with today's society this. Competence relates cognitive, affective, and attitudinal aspects of the 4 measures of global communication competence, namely global mindsite, self-disclosure, cultural mapping, and harmonization of interactions (Chen, 2005). Cultural mapping requires comparing our own culture with other cultures and studying the similarities and differences. There may be confusion and frustration when we notice a difference but after analyzing different aspects, it is important to immerse yourself in other cultures and try to know their community, lastly, aligning the actions contributed to the ultimate goal to successfully interact and share the culture of testimony, the ability of interaction to carry out communication attitudes to get the desired response in a global communication environment without breaking norms and rules of their peers (Chen \& Starosta, 2005). According to Chen and Starosta (2005) in a world communication environment without violating the customs and rules of their peers. Effectiveness and conformity have two important components in this process of being flexible and cultivating a relationship and change. Chen gave a model of world communication that the importance of expanding our way of thinking to incorporate more complex qualities. According to Vicere (2004) thinking globally has become an integral part of our lives as citizens today, at a time when we are more fortunate and interdependent on cultures around the world.

\section{Social Media}

Social media is an essential part of our lives because it promotes connectedness and interdependence of our culturally various world. Media for interaction Social media allows humans to talk and interact with facts that may be fast accessed at the net. Society at this time, there is an increase in the number of users internet has resulted in social media becoming increasingly popular in the patterns and routines of everyday life. Communication that occurs 
in this online context promotes an an interactive talk that increase an information of multiple points of view. On social media, people will have the possibility to express opinion to the general public and participate in conversations and dialogues to the general public and participate in conversations anthrough a common digital medium, which also way that on the same time, everyone is a writer and critic in cyberspace (Georgetown University, 2010).

There are various reasons someone uses social media. First, the need for connection and connection with others is obvious. As supported by Maslow's Hierarchy of Needs (1954), people desire to fulfill their sense of belonging through the help of relationships with other people. After obtaining physiological and protective needs, humans will try to obtain the third need that is owned by Maslow. social media presents possibilities this is where people can talk with others and be part of a different network differently through virtual communities on the internet. In interacting with various people online, people use social media to leverage expertise and find out about various criticisms and perspectives on issues, topics, and activities. maximally vital, social media is used to socialize; means one form of media that allos people to take part in online conversations and dialogues with out meeting different people. Cultural differences affect communication, behavior, and values. Rosen, Stefanone, and Lackaff (2010) say that showing, there are differences between cultures, and these differences have an impact on the way people talk on social networking sites. Cultural differences can understood through Hofstede's five cultural dimensions and the Diffusion idea of Innovation.

With respect to social media, for instance, differences in individualistic cultures and collectivism is clear in person communication and behavioral patterns. Rosen, Stefanone, and Lackaff (2010), explain that people from individualistic cultures acknowledge meeting new people and being seen through lots of giving, as opposed to retaining their existing dates on social networking sites. in step with Boyd and Ellison (2007), social networking sites allow people to create profiles within the system, view profiles of different human beings with whom they percentage a connection, and engage with others inside the system.

\section{Illegal Immigrant}

The term immigrant comes from Latin migration, which means the movement of people from one place to another or country to another place or country. There is a term emigratio, which means moving residents of a region or country out to another region or country. Otherwise, the term immigration means the movement of people from a country to enter the country other. In essence, emigration and immigration are related to the same thing, namely migration population between countries, but what differs is the way they view it. When someone moves to another country, this event is seen as an emigration event, but for visited by the person the event is referred to as an immigration event (Santoso, 2014:14). According to Santoso (2004:21), essentially immigration is a series of officers' activities in the context of providing services and law enforcement, as well as security against traffic in and out of people from and into the territory of a country, as well as supervision of the presence and activities of foreigners while in the country. 1) Immigrant is a person who carries out immigration activities (noun), namely the movement of people from one place to another country to country; 2) Illegal migrants are migrations that occur outside of legal procedures and regulations valid country. In short, the movement of people across national borders that violates applicable immigration rules.

The meaning of illegal can be interpreted as illegal; not according to law; invalid, the foreigner entered Indonesia illegally. Do not have valid identification documents. Based on the meaning of the word mentioned above, illegal immigrants are subjects who move from one country to another other countries illegally or unlawfully. Besides, the transfer in question is 
related to the process of entry/exit from the territory of a country and, the process becomes illegal or unlawful when there is a neglect and abuse of sovereignty the law of the country (Hamidi and Charles Christian, 2015: 26-27). Kim (2008) defines communication as the main measure of immigrant adaptation, with the media playing various roles in this procedure. However, according to McGregor Siegel (2013), that in recent years, the virtual generation has the ability to transform migrant settlements in various fields of socio-political, financial, and cultural integration. Therefore, new technologies can offer migrants with geral records about rights, citizenship and services support local migrants, helping to overcome feelings of isolation via making facts available to migrants of their own language and cultural practices of the country of origin and country their new goal (Dekker \& Engbersen, 2014), promoting language studying through online training programs and inclusion of marginalized immigrant kids (McGregor \& Siegel, 2013).

More particularly in connection to social media, the capacity to convert given by this sort of innovation can primarily be credited to imperative developments in processes communication and collaboration within the setting of movement (Komito, 2011). The distinctive parts of the media social compared to other Internet-based applications depend on the improvement of vagrant social systems and the plausibility of clients to devour, create and share substance and suppositions inside and over systems (Dekker \& Engbersen, 2014). Not Shockingly, most considers on the relationship between social media and integration forms proses have centered on the range of social associations (Brekke, 2008; Elias \& Lemish. 2009; Sawyer \& Chen, 2012), as social organizing locales have given transients with modern shapes of interaction with the have and have communities (Komito, 2011). Inquire about by Elias and Lemish (2009) on Web utilize among youthful foreigners from Russia living in Israel appear that they utilize online chat to associated with companions nearby peers. Inquire about by Sawyer and Chen (2012) moreover found the same design of utilize of social media among Chinese worker understudies within the US.

Additionally, social media stages have been broadly utilized among transients to preserve contact with family individuals and companions in their domestic nation (Elias \& Lemish, 2009; Komito, 2011; Sawyer \& Chen, 2012). The part of social media to bind capital basically established within the require for transients to get enthusiastic bolster, adapting with sentiments of depression and checking companions and family at domestic (Komito, 2011). As a result, a few researchers contend that social media can moderate down the method integration into the have society, as modern participants gotten to be less subordinate on discover companions and create social relationships in their have communities (Brekke, 2008; Komito, 2011). On the other hand, investigate has given solid prove that keep up social relations within the home country and be related with online communities transnationals can offer assistance transients overcome alteration challenges rather than gaining social isolation within the unused society (Elias \& Lemish, 2009). Therefore, Komito (2011) stated that it is not yet clear how social media and new technologies are changing migration patterns earlier and suggested that further research is needed to better understand whether the technology actually facilitates or hinders the integration process across the various social field.

\section{Impact of Social Media on Intercultural Adaptation}

A few investigate ponders have been conducted to explore the affect of social organizing locales on the method of intercultural adjustment. These considers have uncovered that universal understudies, workers, and workers utilize the modern social media for a number of common purposes with cross-cultural acculturation. These objectives incorporate communicating with family individuals them. classmates, companions, and more in their domestic city and have nation (Hendrickson \& Rosen, 2017; Sawyer \& Chen, 2011; W. Chen, 
2010; Sawyer, 2011). Other goals is to procure social capital (Alencar, 2018: Croucher, 2011; Naseri, 2017: Sandel, 2014), and to adjust socially in instructive settings (Ahmad, Mirza, \& Mohd, 2014; Cao \& Zhang, 2012: Forbush \& Foucault-Welles. 2016).

\section{METHOD}

Researchers use qualitative research methods because This form of research allows researchers to be able to describe the object of research in detail holistically based on the social realities that exist in the field. According to Bodgan and Taylor (Moong, 2007: 3) "Subjective strategy as a investigate method that produces information graphic shape of composed or talked words of individuals and discernible behavior. Subjective investigate like this scts to see what is happening within the world and put the discoveries gotten in it (Bungin, 2003: 82). This consider employments a subjective expressive approach with a case study strategy in order to capture the phenomena that exist in the field and then studied in more depth. Reality on the ground. The information obtained in the field is then compiled into a text that emphasizes the problem of process and meaning. The research location is the object and source of data from the place understudy so that The information obtained can provide accurate and truthful data in research. This literature review article uses a qualitative approach with a descriptive analysis method. Literature review contains reviews, summaries, and thoughts about several library sources (articles, books, slides, information from the internet, and etc.) according to the topic discussed. Theoretical foundation, theoretical review, and Literature review are several ways to conduct a literature review. Literature review is a way to find, search for articles, books and other sources such as theses, dissertations, proceedings, which relevant to a particular issue or theory or research of interest to the author. In conducting a review of the literature, what needs to be seen is the need for analyzing, synthesizing, summarizing, or comparing the same literature with the others. Literature review helps writers to decipher how the foundations used in a research.

\section{DISCUSSION AND CONCLUSION}

The focus of individual attention on the process of experience and values that exist in the social life of individuals with social media is used to shape themselves and conceptualize themselves to the meaning of the structure of society through conversations on social media. In addition, cultural differences become socio-cultural factors for immigrants in adapting and adjusting to the social environment. Nature and behavior shown by immigrants in adapting and interacting can form self-concept and understanding of values towards culture shock in adjusting. According to Graham Murdock (1989), every community group will continuously engage in conversation and the creation of meaning and shape the expressive nature of social life. This is what determines the meaning, self-identity, and individual influence in forming ideas and understanding values in interpreting themselves against culture shock and cultural differences (Morissan, 2013).

Culture also includes many things in social life, such as language, ways of communicating, behavior, adaptation, and interaction in adjustment. According to Ellingsworth (1988), behavior and adjustment are intercultural elements of adaptation to individual communication styles (Morissan, 2013). Style is individual behavior or individual communication behavior. Therefore, self-adjustment and individual behavior in adapting can be said to occur because of the perceptual, cognitive, and behavioral dimensions of individuals in self-concepting against culture shock and cultural differences. Adjustment and adaptation 
are needed in social life, especially in culture shock and cultural differences. Language factors, individual traits and beliefs about a new culture are the two main and important things in interacting and adjusting to certain situations (Rokeach, 2013). The process of adjusting to immigrants certainly requires a lot of time in interacting and getting to know a new culture. Therefore, the presence of communication technology such as social media can be used by immigrants to learn about local culture. the use of language and self-concept shown in communicating with the social environment can create an understanding and social assessment of its own, where the language and self-concept used in communication will reject forms of communication that empower all community groups.

Language is a very important communication factor in communicating (Morissan, 2013). In addition, the use of universal language can create an understanding of language that encourages ways and values of understanding a conversational discourse in communicating as well as the self-concept brought by immigrants in behaving and behaving towards culture shock, which is an adjustment factor in communicating and communicating. interact. Culture shock is the adjustment of immigrants in accepting, appreciating and overcoming problems with adjusting to their social environment and social relations in society, of course, there are misunderstandings and differences of opinion between individuals with each other in adapting and interacting. Immigrants Smust be able to manage their own uncertainty and anxiety in adjusting to culture shock. According to Berger (2005), people will experience difficult periods in their lives when they accept uncertainty over the behavior of others (Morissan, 2013). This is an effort to reduce uncertainty and overcome culture shock, which is one of the important dimensions for building social relationships and adjustment in the social environment, both in the new culture and in the culture of origin.

This consider analyzes the basic issues of intercultural communication and relations. This investigates the concept of adjustment, which centers on how people connected and adjust to other societies when they move to a unused put. It is essential to get it intercultural communication since it includes individuals entering unused societies, assembly a new individual who may now not hold the values, standards, o ven beliefs that same with him. Hence, it investigates the method of how people adjust with a unused situation. The U-Curve del was made by Lysgaard (1955) which particularly centers on adjustment somebody ta outside culture. This show is assist amplified to watch the section organize person return upon entry back domestic. The amplified demonstrate is known as The $\mathrm{W}$-curve demonstrate made by Gullahorn and Gullahom (1963).

This bend starts with sentiments of positive thinking and indeed bliss that closes up provide way to disappointment, pressure, and uneasiness as people cannot associated successfully with their unused environment. Specifically, this U curve passes through four levels, namely: Optimistic phase, the first phase depicted is at the top left of the curve U. This phase is filled with excitement, hope, and euphoria as the individual anticipates before entering a new culture. Cultural problems, the second phase in which problems with the environment are just starting developing, for example, due to language difficulties, new traffic systems, new schools, and etc. This phase is usually marked by feelings of disappointment and dissatisfaction. This is the period crisis in culture shock. People become confused and astonished by their surroundings, and can become frustrated and irritable, hostile, irritable, impatient, and even become incompetent. Recovery phase, the third phase where people begin to understand their new culture. On At this stage, people gradually make adjustments and changes in their ways tackling the new culture. People and events in a new environment begin to predictable and less stressful. In the adjustment phase, the last phase, at the top of the right $\mathrm{U}$, people have understood the key elements of the new culture (values, special adaptations, communication patterns, beliefs, etc.). The ability to live in two different cultures is usually 
accompanied by a sense of satisfaction and enjoy. But some things state that, to be able to live in two cultures that, one will need to re-adapt to one's previous culture, and gave rise to the idea of a W Curve, which is a combination of.

\section{REFERENCES}

Ahmad, A. L., Mirza, E., \& Mohd, R. H. (2014). Adaptation and the new media technology: A study on Malaysian students in Australia and United Kingdom. Malaysian Journal of Communication, 30(1), 195-206. https://doi.org/10.17576/jkmjc-2014-3001-10

Alencar, A. (2018). Refugee integration and social media: A local and experiential perspective. Information, Communication \& Society, 21(11), 1588-1603. https://doi.org/10.1080/1369118X.2017.1340500

Brekke, M. (2008). Young refugees in a network society. In J. O. Bærenholdt \& B. Granas (Eds.), Mobility and place: Enacting Northern European peripheries (pp. 103-114). Aldershot: Ashgate.

Chen, Guo-Ming \& Zhang, Kai. (2010). New media and cultural identity in the global society. In Taiwo, Rotimi (Ed.), Handbook of research on discourse behavior and digital communication: Language structures and social interaction (pp. 801-815). Hershey, PA:Idea Group.

Chen, W. (2010). Internet use and intercultural adaptation: A case study on Chinese immigrants in Singapore. Paper presented at the annual meeting of the International Communication Association, New York City, NY.

Croucher, S. M. (2011). Social networking and cultural adaptation: A theoretical model. Journal of International and Intercultural Communication, 4(4), 259-264. https://doi.org/10.1080/17513057.2011.598046 Facebook

Dekker, R., \& Engbersen, G. (2014). How social media transform migrant networks and facilitate migration. Global Networks, 14, 401-418. doi:10.1111/glob.12040

Elias, N., \& Lemish, D. (2009). Spinning the web of identity: The roles of the internet in the lives of immigrant adolescents. New Media \& Society, 11, 533-551. doi:10.1177/1461444809102959

Forbush, E., \& Foucault-Welles, B. (2016). Social media use and adaptation among Chinese students beginning to study in the United States. International Journal of Intercultural Relations, 50, 1-12. https://doi.org/10.1016/j.ijintrel.2015.10.007

Gudykunst, William B. (2003). Cross-Cultural and Intercultural Communication. Thousand Oaks: Sage.

Gudykunts, William B dan Kim, Young Y. (2003). Communicating with Stranger, 4 Edition. USA: Mc-Graw Hill Companies, Inc.

Hendrickson, B., \& Rosen, D. (2017). Insights into New Media Use by International Students: Implications for Cross-Cultural Adaptation Theory. Social Networking, 6, 81-106. https://doi.org/10.4236/sn.2017.62006

Kamus Besar Bahasa Indonesia (Edisi Ketiga). 2002. Jakarta: Balai Pustaka.

Kim, Y. S. (2008). Communication experiences of American expatriates in South Korea: A study of cross-cultural adaptation. Human Communication, 11, 511-529.

Komito, L. (2011). Social media and migration: Virtual community 2.0. Journal of the American Society for Information Science and Technology, 62, 1075-1086. doi:10.1002/asi.21517

McGregor, E., \& Siegel, M. (2013). Social media and migration research (Working Paper No. 2013068). Maastricht: United Nations University-Maastricht Economic and Social Research Institute on Innovation and Technology (MERIT). 
Morissan. (2013). Teori Komunikasi Individu Hingga Massa. Jakarta: PT Prenada Media Group

Sawyer,R.,\&Chen,G.(2012). Theimpact ofsocial media on intercultural adaptation. Intercultural Communication Studies, 21, 151-169. Retrieved from http://digitalcommons.uri.edu/cgi/ viewcontent.cgi? article $=1033 \&$ context $=$ com_facpubs

Scholten, P., \& Van Nispen, F. (2015). Policy analysis and the 'migration crisis': Introduction. Journal of Comparative Policy Analysis: Research and Practice, 17(1), 1-9. doi:10.1080/ 13876988.2015.1006408

Strang,A.,\&Ager,A.(2010). Refugee integration: Emerging trends and remaining agendas. Journal of Refugee Studies, 23, 589-607. doi:10.1093/jrs/feq046

\section{About the authors}

Tessa Shasrini, lecturer in department of Communication Science, Faculty of Communication Science, Universitas Islam Riau, Pekanbaru and Doctoral student in Faculty of Communication Science, University Putra Malaysia (UPM).

Yudi Daherman, lecturer in department of Communication Science, Faculty of Communication Science, Universitas Islam Riau, Pekanbaru and Doctoral student in Communication Science, University Sahid Jakarta (USahid) 